\title{
Magnetic Resonance Image Findings ar Surgical Considerations in T1-2 Disc Herniation
}

\author{
H. Caner, B.F. Kilinçoglu, S. Benli, N. Altinörs, M. Bavbek
}

\begin{abstract}
Objective: To report a case of disc herniation at T1-2. Clinical presentation: A 57-yearold man presented with hand weakness, Horner's syndrome, and pain radiating along the medial aspect of one upper extremity. Magnetic resonance imaging demonstrated extruded T1-2 disc herniation with upward herniation of a sequestrated fragment. Intervention: An anterior approach was used to excise the disc, that was compressing the spinal cord and the T1 nerve root. All the patient's symptoms resolved completely, including Horner's syndrome. Conclusion: Anterior discectomy may be the simplest and most effective method for disc excision and relief of spinal cord and T1 nerve root compression.
\end{abstract}

RÉSUMÉ: Observations à la RMN et considérations chirurgicales dans la hernie discale D1-D2. Objectif: Rapporter un cas de hernie discale au niveau de D1-D2, une condition qui présente souvent un défi diagnostique au point de vue clinique et un défi dans l'approche chirurgicale. Présentation de cas: Un homme âgé de 57 ans a consulté pour une faiblesse musculaire au niveau de la main, un syndrome de Horner et une douleur irradiant à la région médiale du membre supérieur. La RMN a montré une hernie discale au niveau de D1-D2 avec hernie vers le haut d'un fragment séquestré. Intervention: Une approche antérieure a été utilisée pour exciser le disque comprimant la moelle épinière et la racine nerveuse D1. Tous les symptômes du patient, incluant le syndrome de Horner, ont régressé. Conclusion: La discectomie antérieure peut être la méthode la plus simple et la plus efficace pour exciser le disque et soulager la compression de la moelle épinière et de la racine nerveuse D1.

Can. J. Neurol. Sci. 2003; 30: 152-154

Thoracic disc herniation accounts for $0.15-4.4 \%$ of all disc herniations. Seventy-five percent of these disc problems occur below T8, with a peak of $26 \%$ at T11-12. The upper thoracic spine (T1-5) is the region least often affected, with only $6 \%$ of all thoracic disc herniations occurring here. ${ }^{1-7}$ To date, a total of 31 cases of T1-2 disc herniation have been reported in the literature and all but one of these was diagnosed by myelography, computed tomography (CT), or CT myelography. Posterior surgical approaches were performed in all except one case, in which an anterior approach was used..$^{8-11}$

In this article, we present a case of T1-2 fragmented disc herniation. The patient's symptoms, neurological findings, and magnetic resonance imaging (MRI) results are described, and the efficacy of the anterior surgical approach is discussed.

\section{CASe RePORT}

A 57-year-old man presented with complaints of pain in his left arm, forearm, anterior upper chest, and neck; numbness on the medial aspect of his left arm; and mild weakness in his left hand. His wife had noticed ptosis of his left eye. A neurological examination revealed left Horner's syndrome, diminished sensation in the left axilla and on the medial aspect of the left arm, and mild weakness of the intrinsic muscles of the left hand. Tendon reflexes were normal. Since these findings suggested pathology at the upper thoracic level, the routine cervical MRI scan was extended to include this region of the spine. The images demonstrated sequestrated T1-2 disc herniation, with a sequestrated disc fragment that had migrated upward posterior to the T1 vertebra. Intravenous contrast was administered in order to rule out an extramedullary tumor, and this was associated with peripheral lesion enhancement, characteristic of fragmented disc herniation (Figure a, b, c).

The patient's neck was short, and approaching the T1-T2 was difficult without splitting the manubrium. The manubrium was therefore split, the left brachiocephalic vein and brachiocephalic trunk were retracted inferiorly, and the trachea and esophagus were retracted laterally. Dissection of the prevertebral longus colli muscles exposed the upper thoracic vertebral bodies. The location of the T1-2 intervertebral disc space was verified by $\mathrm{x}$-ray. The disc material, including the

From the Departments of Neurosurgery and Neurology, Baskent University, Faculty of Medicine, Ankara, Turkey.

Received May 14, 2002. ACCEPTEd in FINAL FORm November 20, 2002. Reprint requests to: Hakan Caner, Department of Neurosurgery, Baskent University, School of Medicine, Bahcelievler 10. Sokak, Ankara 06490 Turkey 


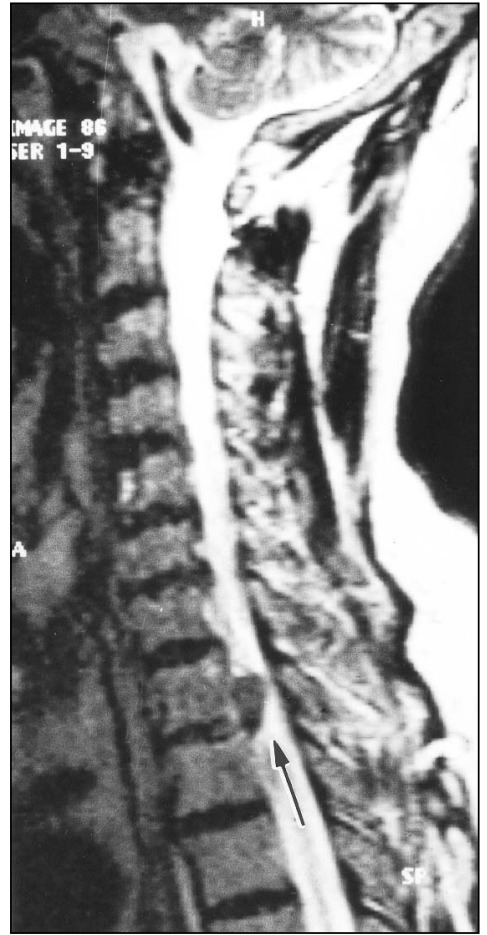

Figure a: Sagital T2-Weighted MR images of sequestrated T1-2 disc herniation

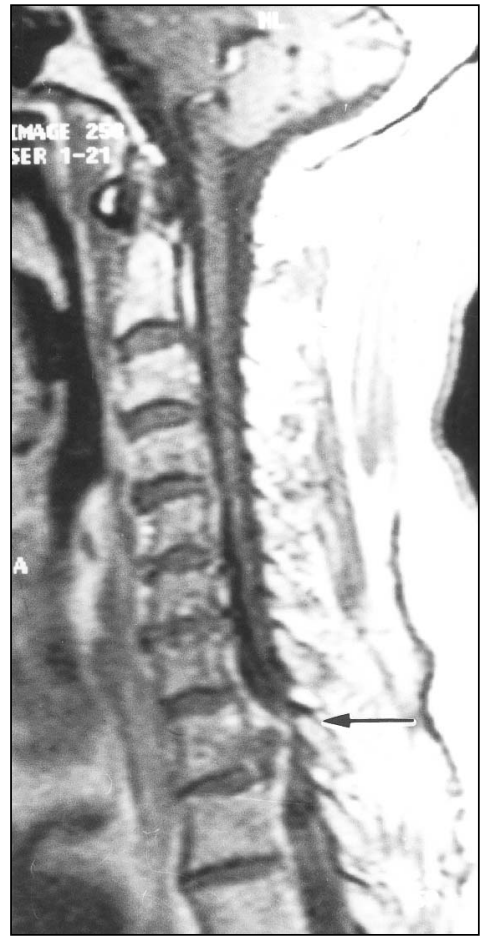

Figure b: Sagital T1-Weighted with gadolinium demonstrates peripherally enhanced sequestrated disc.

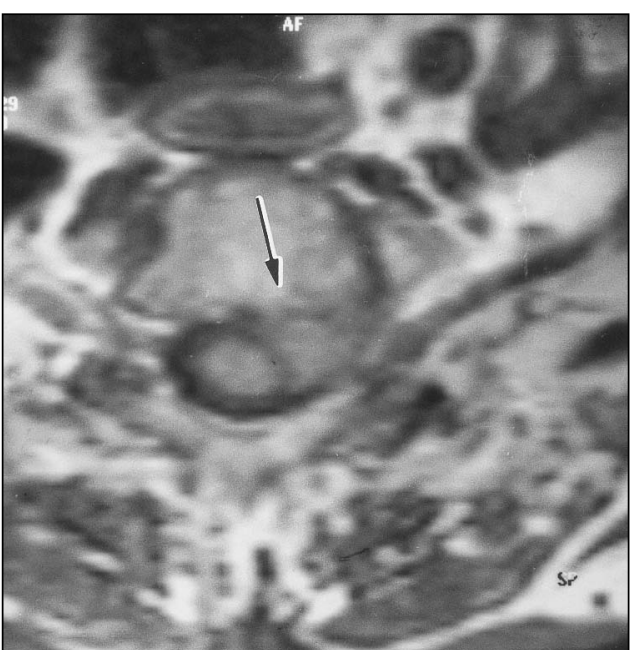

Figure c: Axial T1-Weighted MR image of sequestrated T1-2 disc herniation demonstrates compression of spinal cord and T1 root subligamentous disc fragment, was totally excised using microsurgical technique.

In the early postoperative period, the patient reported no pain or numbness in his left arm. A neurological examination revealed total recovery from Horner's syndrome, as well as resolution of the weakness in his hand muscles. The patient was discharged one day after surgery.

\section{DISCUSSION}

Upper thoracic disc herniation is rare. Patients can easily be misdiagnosed with cervical disc herniation or thoracic outlet syndrome. The common complaints in cases of this type are pain in the arm, shoulder, and neck (60\%), as well as sensory (23\%) and motor changes $(18 \%) .^{1,12-15}$ Radiculopathy is the most frequent finding $(87 \%)$ in published cases, and Horner's syndrome is seen in $21 \%$ of patients. ${ }^{15-18}$ Cervical MRI extended to include the upper thoracic region is the most appropriate diagnostic tool in these cases. In addition to the neurological findings, the images are also helpful for planning the optimal surgical approach. Our patient exhibited signs of radiculopathy, and Horner's syndrome. Since the axial MR view demonstrated a paracentral sequestrated disc that displaced and slightly depressed the spinal cord laterally, anterior discectomy was chosen as the surgical approach. Although Sharan et al ${ }^{19}$ reported that anterior discectomy without sternotomy is possible in certain cases for upper level thoracic disc disease, in our case the neck was short and it was impossible to reach T1-2 level through a suprasternal incision.

There are few cases in the literature in which T1-2 disc excision has been performed via an anterior approach. Rossitti et $\mathrm{al}^{10}$ reported an approach with sternotomy. Nakahara et $\mathrm{al}^{20}$ reported a case with myelopathy and Sharan et $\mathrm{al}^{19}$ reported four of seven cases that were operated on by an anterior approach without sternotomy. Sharan et $\mathrm{al}^{19}$ reported that the T1-2 disc level is usually above the sternum and discectomy is possible via suprasternal approach. Before the surgery the relation of the sternal notch to thoracic vertebrae should be examined by x-ray to estimate the thoracic level approachable anteriorly without sternotomy. Other published accounts of T1-2 disc herniation have involved posterior approaches, including laminectomy with foraminotomies, laminectomy with transdural disc excision, and thoracotomy with lateral extracavitary exposure..$^{8,9,11,15,18,21,22}$ In these patients, all of the symptoms except Horner's syndrome resolved postoperatively. ${ }^{15,16,18}$ In contrast, our patient's Horner's syndrome resolved immediately after surgery. We believe that this result was associated with total removal of the disc material that had been laterally compressing the spinal cord, rather than with T1 nerve root decompression alone. Anterior discectomy results in total decompression of the intermediolateral cell column of gray matter between $\mathrm{C} 8$ and $\mathrm{T} 1$, where the preganglionic sympathetic nerve fibers originate and join the T1 nerve root. ${ }^{16}$ Total disc excision is not possible when posterior or posterolateral approaches are used.

It is difficult to access the T1-2 vertebrae by thoracotomy because the thorax is very narrow at this level. The anterior approach also presents challenges, in that the depth of the surgical field requires longer surgical instruments, especially 
curets. Also, great care must be taken to protect the left brachiocephalic vein and brachiocephalic trunk. These vessels must be handled gently in order to prevent facial edema due to excessive compression of the brachiocephalic vein, or cerebral infarction due to plaque embolism from arterial compression and handling.

\section{REFERENCES}

1. Alberico AM, Sahni KS, Hall JA, et al. High thoracic disc herniation. Neurosurgery 1986; 19:449-451.

2. Arce CA, Dohrmann GJ. Thoracic disc herniation, improved diagnosis with computed tomographic scanning, and review of the literature. Surg Neurol 1985; 23:356-361.

3. Arseni C, Nash F. Protrusion of thoracic intervertebral discs. Acta Neurochir 1963;11:3-33.

4. Arseni C, Nash F. Thoracic intervertebral disc protrusion. A clinical study. J Neurosurg 1960; 17: 418-430.

5. Blumenkopf $\mathrm{B}$. Thoracic intervertebral disc herniations: diagnostic value of magnetic resonance imaging. Neurosurgery 1988; 23:3640.

6. Logue V. Thoracic intervertebral disc prolapse with spinal cord compression. J Neurol Neurosurg Psychiatry 1952; 15:227-241.

7. Love JG, Schorn VG. Thoracic-disc protrusions. JAMA 1965; 191:627-631.

8 Murphey F, Simmons JC, Brunson B. Surgical treatment of laterally ruptured cervical discs. Review of 648 cases, 1939 to 1972. J Neurosurg 1973; 38:679-683.

9. Patterson RH Jr, Arbit E. A surgical approach through the pedicle to protruded thoracic discs. J Neurosurg 1978; 48:768-772.

10. Rossitti S, Stephensen H, Ekholm S, von Essen C. The anterior approach to high thoracic (T1-T2) disc herniation. $\mathrm{Br} \mathrm{J}$ Neurosurg 1993; 7:189-192.

11. Winter RB, Siebert R. Herniated thoracic disc at T1-T2 with paraparesis. Transthoracic excision and fusion - case report with 4-year follow-up. Spine 1993; 18:782-784.

12. Hamlyn PJ, Zeital T, King TT. Protrusion of the first thoracic disc. Surg Neurol 1991; 35:329-331.

13. Korovessis PG, Stamatakis M, Michael A, Baikousis A. Three-level thoracic disc herniation: case report and review of the literature. Eur Spine J 1997; 6:74-76.

14. Kumar R, Buckley TF. First thoracic disc protrusion. Spine 1986; 11:499-501.

15. Morgan H. Abood C. Disc herniation at T1-2. J Neurosurg 1998; 88: 148-150.

16. Gelch MM. Herniated thoracic disc at T1-2 level associated with Horner's syndrome. Case report. J Neurosurg 1978; 48:128-130.

17. Hammon WM. Extruded upper thoracic disc causing Horner's syndrome. Report of a case. Med Ann Dist Columbia 1968; 37:541-542.

18. Lloyd TV, Johnson JC, Paul DJ, et al. Horner's syndome secondary to herniated disc at T1-T2. AJR Am J Roentgenol 1980;134:184-185.

19. Sharan AD, Przybylski GJ, Tartaglino L. Approaching the upper thoracic vertebrae without sternotomy or thoracotomy: a radiographic analysis with clinical application. Spine 2000; 25:1910-1916,

20. Nakahara S, Sato T. First thoracic disc herniation with myelopathy. Eur Spine J 1995, 4:366-367.

21. El-Kalliny M, Tew JM Jr, van Lovern H, et al. Surgical approaches to thoracic disc herniations. Acta Neurochir 1991; 111:22-32.

22. Fujimura $Y$, Nakamura M, Matsumoto M. Anterior decompression and fusion via the extrapleural approach for thoracic disc herniation causing myelopathy. Keio J Med 1997; 46:173-176. 